\title{
TIME SERIES ANALYSIS OF REMOTE SENSING OBSERVATIONS FOR CITRUS CROP GROWTH STAGE AND EVAPOTRANSPIRATION ESTIMATION
}

\author{
S. A. Sawant ${ }^{\mathrm{a}, *}$, M. Chakraborty ${ }^{\text {a }}$, S. Suradhaniwar ${ }^{\text {a }}$, J. Adinarayana ${ }^{\text {a }}$, S. S. Durbha ${ }^{\text {a }}$ \\ ${ }^{a}$ Centre of Studies in Resources Engineering, Indian Institute of Technology Bombay, Powai 400 076, Mumbai, India - \\ (suryakant_sawant, 143310006, 134316002, adi, sdurbha)@iitb.ac.in
}

Commission VIII, WG VIII/8

KEY WORDS: Time series, Landsat, Citrus crop, Crop growth stage, Evapotranspiration estimation, Crop water requirement

\begin{abstract}
:
Satellite based earth observation (EO) platforms have proved capability to spatio-temporally monitor changes on the earth's surface. Long term satellite missions have provided huge repository of optical remote sensing datasets, and United States Geological Survey (USGS) Landsat program is one of the oldest sources of optical EO datasets. This historical and near real time EO archive is a rich source of information to understand the seasonal changes in the horticultural crops. Citrus (Mandarin / Nagpur Orange) is one of the major horticultural crops cultivated in central India. Erratic behaviour of rainfall and dependency on groundwater for irrigation has wide impact on the citrus crop yield. Also, wide variations are reported in temperature and relative humidity causing early fruit onset and increase in crop water requirement. Therefore, there is need to study the crop growth stages and crop evapotranspiration at spatio-temporal scale for managing the scarce resources. In this study, an attempt has been made to understand the citrus crop growth stages using Normalized Difference Time Series (NDVI) time series data obtained from Landsat archives (http://earthexplorer.usgs.gov/). Total 388 Landsat 4, 5, 7 and 8 scenes (from year 1990 to Aug. 2015) for Worldwide Reference System (WRS) 2, path 145 and row 45 were selected to understand seasonal variations in citrus crop growth. Considering Landsat 30 meter spatial resolution to obtain homogeneous pixels with crop cover orchards larger than 2 hectare area was selected. To consider change in wavelength bandwidth (radiometric resolution) with Landsat sensors (i.e. 4, 5, 7 and 8) NDVI has been selected to obtain continuous sensor independent time series. The obtained crop growth stage information has been used to estimate citrus basal crop coefficient information $(\mathrm{Kcb})$. Satellite based Kcb estimates were used with proximal agrometeorological sensing system observed relevant weather parameters for crop ET estimation. The results show that time series EO based crop growth stage estimates provide better information about geographically separated citrus orchards. Attempts are being made to estimate regional variations in citrus crop water requirement for effective irrigation planning. In future high resolution Sentinel 2 observations from European Space Agency (ESA) will be used to fill the time gaps and to get better understanding about citrus crop canopy parameters.
\end{abstract}

\section{INTRODUCTION}

In agrarian economies water plays a major role as it directly affects the crop productivity thereby addressing the food security. The multi-dimensional nature of climate change in the form of droughts, intense storms, erratic weather, etc. has major impact on regional water resources (Agrawal, 2008). The consumptive use of water by plants is extensively studied. Experimental and theoretical methodologies are formed for estimation of consumptive use of water through transpiration and evaporation together referred as evapotranspiration (ET). In actual evapotranspiration (ETa) estimation, ground-based techniques such as lysimeters, energy flux towers, scintillometers, meteorological observations, sap flow, etc. avail site-specific parameters at high temporal resolution (Allen et al., 2005). Theoretical estimation techniques for ET estimation include methods based on energy and mass balance. Meteorological parameters (air temperature, relative humidity, wind speed, solar radiation, etc.) obtained from weather station are used for ET estimation. Observation of these parameters over regional scale can be possible with high temporal resolution satellite remote sensing and proximal field based sensing systems (Prihodko and Gowrad 1997; Cresswell et al., 1999).

The regional crop water balance models require agrometeorological, soil and crop parameters on spatio-temporal scale. To estimate CWR on spatial scale there is need for point / pixel based crop evaporative fraction / crop coefficient which is the ratio of actual crop ET to potential ET. Studies have found that crop coefficient $(\mathrm{Kc})$ varies with crop growth rate, planting density and management practices. FAO-56 based generic Kc curves often don't match with actual crop water use therefore there is need for site specific Kc estimates (Glenn et al., 2011). The basal crop coefficients (Kcb) are related to crop light interception or canopy cover (Choudhury et al., 1994). Various Studies have shown that satellite derived canopy cover and Vegetation Indices (VI's) have strong correlation with Kc (Tasumi et al., 2014; Er-Raki et al., 2007; Mateosa et al., 2013).

The VI's such as, Leaf Area Index (LAI), Normalized Difference Vegetation Index (NDVI), Soil Adjusted Vegetation Index (SAVI) and Transformed Soil Adjusted Vegetation Index

* Corresponding author 
(TSAVI) are widely used for ETa estimation (Glenn et al., 2011; Choudhury et al., 1994). The eddy covariance based energy flux towers, lysimeters and actual soil moisture measurements are used for validating the relationship between observed and estimated Kc for selected crops (Dugo et al., 2013; Galleguillos et al., 2011; Mateosa et al., 2013). The important advantage of RS based crop VI's are they help in estimation of crop water requirement on field-by-field basis (Glenn et al., 2011). Attempts are being made to develop reflectance-based crop coefficients for numerous individual crops, including corn, wheat, alfalfa, cotton, potato, sugar beet, vegetables, grapes and orchard crops. The results have shown that VI's can be used to predict ET over fields of mixed crops, allowing them to be used to monitor ET over entire irrigation districts (Glenn et al., 2011).

In horticultural crops VI based crop coefficients limit to capture crop moisture stress effects (Glenn et al., 2011). ET estimation using surface energy balance (Bastiaanssenet al., 1998a, 1998b) accounts satellite observation of single time event and it is difficult to overcome data gaps occurring due to cloud cover. $\mathrm{Mu}$ et al., (2007) proposed methodology for satellite based actual ET estimation by combining surface energy balance and Penman-Monteith (PM) reference ET estimation. The duration of horticultural crops is longer and it is possible to understand the temporal variations in the vegetation growth using satellite based remote sensing sensors. As variable rate of irrigation is required for different regions in the field spatial resolution of available ET products is large and not suitable for small to medium agriculture areas (i.e. sizes ranging between 2 and 10 ha.).

Satellite based earth observation (EO) platforms have proved capability to spatio-temporally monitor changes on earth surface. Long term satellite missions have provided huge repository of optical remote sensing datasets. United States Geological Survey (USGS) Landsat program is one of the oldest sources of optical EO datasets. This historical and near real time EO archive is rich source of information to understand the seasonal changes in the horticultural crops. Orange / mandarin is perennial crop (crop duration ranges between 15 to 20 years) the total water requirement exceeds far more than other seasonal short duration crops (GarciaTejero et al., 2010; Shirgure et al., 2014). Also, wide variations are reported in temperature and relative humidity causing early fruit onset and increase in crop water requirement. Therefore, there is need to study the crop growth stages and crop evapotranspiration at spatio-temporal scale.

The main objectives of this study are, to understand long term trends in horticultural crop using satellite based NDVI time series observations. To adjust crop coefficient values based on crop growth stages and provide methodology to estimate field level variations in crop ET for long duration crops.

\section{MATERIALS AND METHODS}

The proposed framework combines all necessary processes to calibrate and validate regional scale citrus crop water balance. The study area comprises of four villages (Benoda, Bargaon, Goregaon and Nagziri) from major Citrus (Orange) growing region of Amravati district, Maharashtra, India (Figure 1 a). In recent years the prosperity of citrus cultivation of this region has been affected by over exploitation of groundwater (NRAA, 2011).

Time series of NDVI was constructed from Landsat surface reflectance product to understand the citrus crop growth stages (EarthExplorer, 2016). The study area is completely covered by one Worldwide Reference System (WRS) 2, tile with path 145 and row 045 . Total 388 Landsat 4, 5, 7 and 8 scenes (from year 1990 to Aug. 2015) were selected to understand seasonal variations in citrus crop growth. Considering 30 meter spatial resolution of Landsat sensor to obtain homogeneous pixels with crop cover orchards larger than 2 hectare area was selected (Figure $1 \mathrm{~b}$ ). To consider change in wavelength bandwidth (radiometric resolution) of Landsat sensors (i.e. 4, 5, 7 and 8) NDVI has been selected to obtain continuous sensor independent time series. The subset and stacking operations were performed on the surface reflectance data tile. Each image stack comprised of eight bands Blue, Green, Red, NIR, SWIR1, SWIR2, Thermal Infra Red (TIR) and cloud mask. All stacks of images were arranged with metadata for time series extraction.

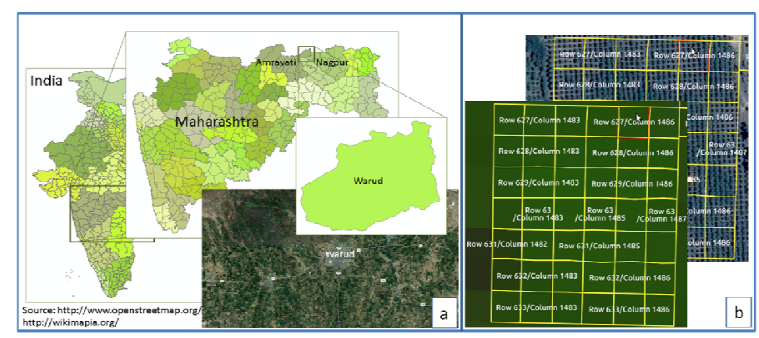

Figure 1. a) Study Area and b) Example of selected Landsat pixels covering citrus land use. The vector layer is overlaid on Landsat and high resolution image of citrus plot.

The temporal surface reflectance values from stacked time series were extracted for pixels of selected citrus orchards using open source YATSM and Time Series tools (TSTools) in Quantum GIS software (Holden C.E., 2015 a and b; QGIS, 2013). Total ten citrus plots covering 413 Landsat pixels were selected for time series analysis. Cloud mask flag was used to obtain cloud free values of each pixel (Figure 2). Figure 2 shows data available from all Landsat (i.e. 4, 5, 7 and 8 sensor) scenes. In this study time series data from year 2005 was selected due to two main reasons, a) availability of cloud free data points is more from year 2005 and b) the year of planting for selected citrus orchards ranges between 1998 and 2002.

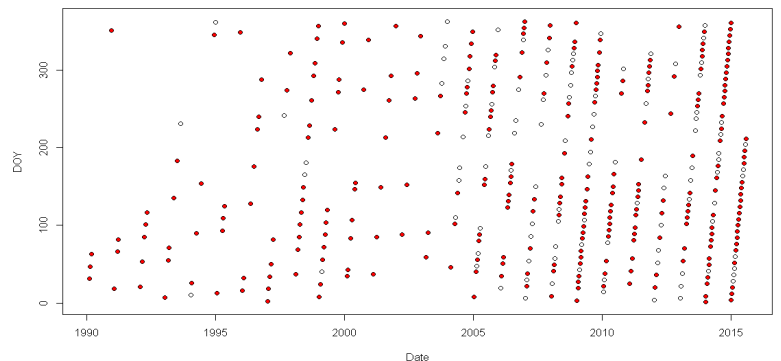

Figure 2. Distribution of Landsat scenes over temporal scale. Filled points show cloud free while open points indicate cloud cover scenes. 
The data processing flowchart for crop ET estimation combines inputs from VI time series and weather observations from agrometeorological monitoring system (Figure 3). The extracted time series for selected pixel was filtered for cloud cover and converted into NDVI time series. The NDVI time series data was smoothened using logistic regression based smoothing algorithm used in BFAST (Verbesselt et al., 2012; Verbesselt et al., 2010). Plot wise average NDVI time series was analyzed for understanding the seasonality in the citrus crop. Methodology for analysis of land surface phenology provided by Forkel et al. (2013) has been used to identify the citrus crop growth stages. The estimated crop growth stages were compared with the actual citrus crop growth stages provided by National Research Centre for Citrus (Shirgure et al., 2014).

In semi-arid tropics with scarce weather stations and unavailability of costly precision validation techniques such as field Lysimeters and Energy Flux Towers, there is a need to consider pre-calibrated VI based relation/model to estimate crop coefficient (Kc). Choudhury et al., (1994), Bausch and Neale (1987), Bausch (1993) and Neale et al., (1990) have also used NDVI based equation for Kcb estimation.

$$
K_{c b}=1.1875 \times N D V I+0.05
$$

where $\quad \mathrm{Kcb}=$ Basal crop coefficient

$$
\text { NDVI = Normalized Difference Vegetation Index }
$$

Rafn et al. (2008) have evaluated method for estimating irrigated crop-ET coefficients from remotely sensed data. Authors suggested that Kc estimation equation has application in wide geographical area. The field validated NDVI-Kc relationship provided by O'Connell et al. (2010) for citrus crop was used to estimate $\mathrm{Kc}$ values. The estimated $\mathrm{Kc}$ was then compared with the crop growth stage based FAO Kc values (Allen et al., 1998). Finally, actual ET for citrus crop was estimated using PM equation provided by Allen et al. (1998).

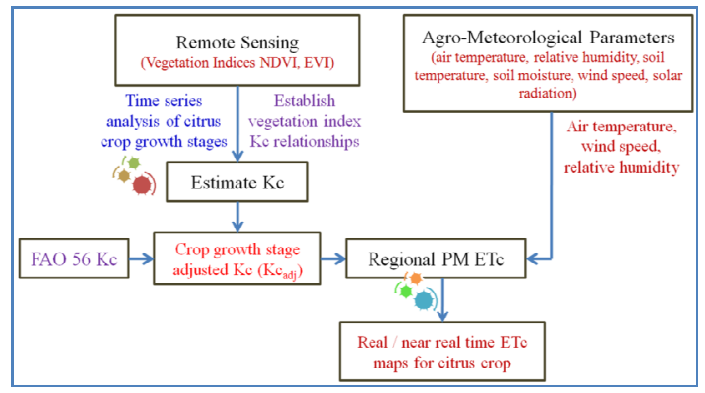

Figure 3. Data processing flowchart for RS based citrus crop ET estimation

The results on satellite derived citrus crop phenological stages, adjustment of $\mathrm{Kc}$ and estimation of ET are discussed in subsequent section.

\section{RESULTS AND DISCUSSIONS}

In the study area two flowering seasons locally called Ambiya (starting from end of winter months i.e. Feb.-March) and Mrig (start of monsoon months June-July) are followed. Flowering season dependent on southwest monsoon rains (Mrig) is prominently followed due dependency on groundwater for irrigation and difficulty to maintain orchards during hot summer months.

Figure 4 shows raw NDVI (non smoothed) time series for selected representative plots. It is observed that NDVI time series has uneven spikes and gaps due to cloud cover.
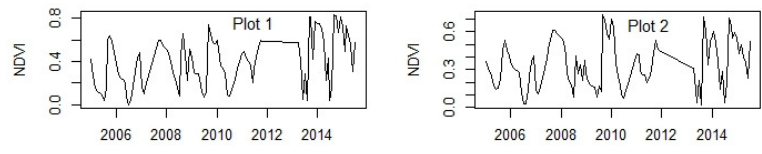

Time

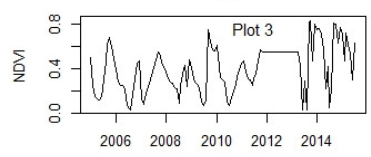

Time

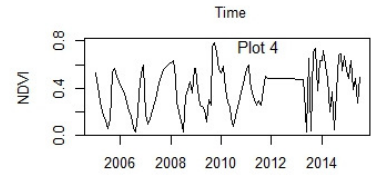

Time

Figure 4. Raw NDVI time series observed over selected Citrus orchards

Canopy cover, tree spacing, training and pruning activities have impact on the infield variation of NDVI estimates. Monthly average values are used for filling gaps and uneven spikes in time series (Figure 5). The gap filled NDVI time series has been used for citrus crop growth stage detection.

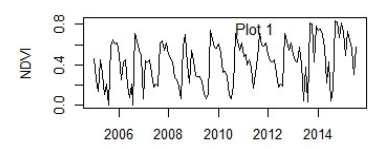

Time

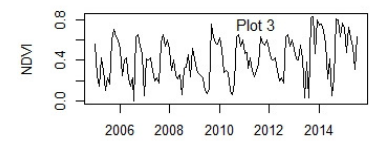

Time

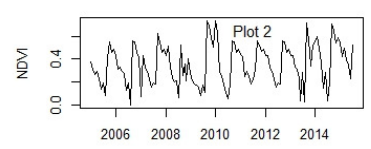

Time

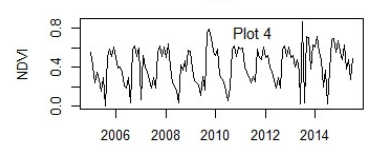

Time
Figure 5. Gap filled NDVI time series of selected citrus plots

The results of citrus crop growth stage detection algorithm estimates day of year for Start of Season (SOS), Position of Peak (POP), End of Season (EOS), Position of Trough (POT), Mean Spring value (MSP) and Rate of Spring Greenup (RSP). The complete cycle of phenological changes in citrus crop canopy are captured in Figure 6. The cropping season starts from month of July and ends during next year Feb. to March. Crop water stress during summer months causes decrease in foliage this effect is clearly captured in the NDVI curve (Figure $6)$.
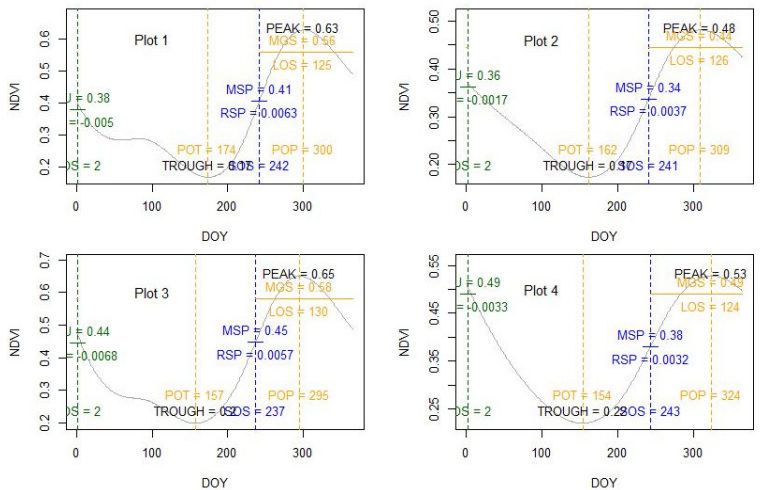

Figure 6. Estimated citrus crop growth stages for selected plots 
The plot wise mean of SOS, EOS, POP or maximum NDVI value and POT or minimum NDVI value are shown in Table 1. Day of SOS and minimum NDVI has minimum plot to plot variations than EOS and peak NDVI. The local variation in citrus crop growth stages is caused mainly due to the crop management practices. Day of SOS for all plots lies in the month of July which justifies the dependency on the southwest monsoon. Whereas day of minimum NDVI lies in the summer months (i.e. May and June) which indicates the duration of low canopy growth due to peak water stress.

\begin{tabular}{|c|c|c|c|c|c|}
\hline $\begin{array}{c}\text { Plot } \\
\text { ID }\end{array}$ & $\begin{array}{c}\text { Ground } \\
\text { truth } \\
\text { samples }\end{array}$ & $\begin{array}{c}\text { Start of } \\
\text { Season }\end{array}$ & $\begin{array}{c}\text { End } \\
\text { of } \\
\text { Season }\end{array}$ & $\begin{array}{c}\text { Peak } \\
\text { NDVI }\end{array}$ & $\begin{array}{c}\text { Trough/ } \\
\text { minimum } \\
\text { NDVI }\end{array}$ \\
\cline { 3 - 6 } & & DOY & DOY & DOY & DOY \\
\hline 1 & 45 & 223 & 187 & 281 & 152 \\
2 & 25 & 247 & 50 & 51 & 187 \\
3 & 24 & 232 & 30 & 288 & 140 \\
4 & 68 & 230 & 140 & 283 & 152 \\
5 & 24 & 196 & 16 & 277 & 107 \\
6 & 32 & 232 & 29 & 161 & 149 \\
7 & 92 & 236 & 143 & 226 & 165 \\
8 & 35 & 240 & 88 & 286 & 168 \\
9 & 36 & 205 & 4 & 147 & 119 \\
10 & 32 & 232 & 29 & 161 & 149 \\
\hline
\end{tabular}

Table 1. Within field variations in citrus crop growth stage parameters

Estimated crop growth seasons are used for assigning FAO Kc values. Figure 7 shows variations in NDVI based Kc and FAO recommended $\mathrm{Kc}$. FAO recommended $\mathrm{Kc}$ values are close to NDVI based Kc values during peak growth stage (i.e. maximum NDVI). Whereas, FAO based approach over estimates $\mathrm{Kc}$ values during crop water stress period. The root mean square error between FAO and NDVI based Kc estimates varies between 0.2 and 0.29 which indicates that $\mathrm{Kc}$ estimates based on long term NDVI pattern can used for crop ET estimations in citrus crop. However, there is still need to verify the exact variations of NDVI Kc estimates by designing field experiments (e.g. ET flux tower, Lysimeter, pan evaporation, etc.).
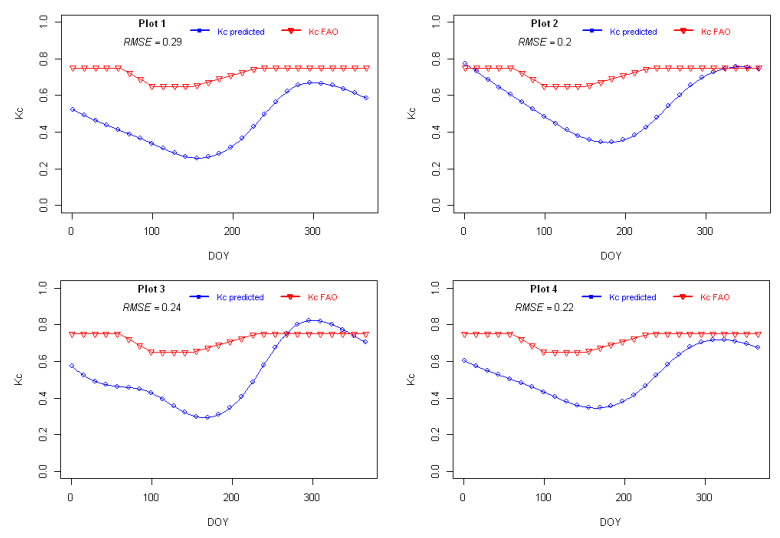

Figure 7. Predicted and FAO Kc curves for selected citrus plots

Weather data from regional automatic weather station has been used to estimate the reference ET using PM equation (Allen et al., 1998). Crop growth stage adjusted NDVI based Kc values are used for citrus crop ET estimation (Figure 8). Figure 8 shows crop ET estimates for selected citrus plot 1 for crop year 2014-2015.

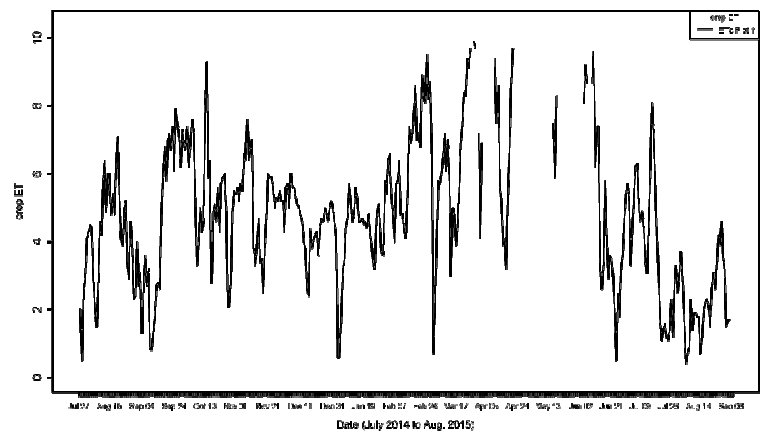

Figure 8. Citrus crop ET estimates for plot 1

It is challenging to validate the ET estimates in semi-arid areas with sparse coverage of weather monitoring stations. The proposed NDVI based Kc estimation methodology can be successfully adopted for field level crop water requirement estimation in long duration tree crops (e.g. Guava, Peach, Mango, etc.)

\section{CONCLUSIONS}

In semi-arid catchments with very few weather observation stations, the RS time series based approach found effective in estimation of crop ET. The proposed approach (i.e. with satellite and proximal sensing systems) combines crop and weather parameters for actual ET estimation. There is need for verification of NDVI based Kc estimation method in citrus crop using eddy covariance techniques used in ET flux towers. The results show that time series EO based crop growth stage estimates provide better information about geographically separated citrus orchards. The information on crop growth stages has potential application in predicting the citrus crop water requirement and designing irrigation schedules.

\section{FUTURE WORK}

Attempts are being made to estimate regional variations in citrus crop water requirement for effective irrigation planning. In future high resolution Sentinel 2 observations from European Space Agency (ESA) will be used to fill the time gaps and to get better understanding about citrus crop canopy parameters. ET flux tower is being deployed in the study area to establish relationship between vegetation indices of citrus crop and field measurements fluxes of water vapour, $\mathrm{CO} 2$, etc.

\section{ACKNOWLEDGEMENTS}

This is a part of research and development work supported by Information Technology Research Academy (ITRA), Media Lab Asia, Department of Electronics and Information Technology (DeitY), Ministry of Communications and Information Technology, Government of India [ITRA/15(66)/Water/PDMH/02/dated-21.09.2013]. Landsat satellite data was availed from the U.S. Geological Survey (EarthExplorer). 


\section{REFERENCES}

Agrawal, A., 2008. The role of local institutions in adaptation to climate change.The Social Dimensions of Climate Change, Social Development Department, The World Bank, Washington DC. http://www.icarus.info/wpcontent/uploads/2009/11/agrawal-adaptation-institutionslivelihoods.pdf (6 Mar. 2014).

Allen, R.G., Pereira, L.S., Raes, D. and Smith, M., 1998. Crop evapotranspiration-Guidelines for computing crop water requirements-FAO Irrigation and drainage paper 56. FAO, Rome, 300(9), p.D05109.

Allen, R.G., Tasumi, M., Morse, A. and Trezza, R., 2005. A Landsat-based energy balance and evapotranspiration model in Western US water rights regulation and planning. Irrigation and Drainage Systems, 19(3-4), pp. 251-268.

Bastiaanssen, W.G.M., Menenti, M., Feddes, R.A. and Holtslag, A.A.M., 1998a.A remote sensing surface energy balance algorithm for land (SEBAL). 1. Formulation. Journal of hydrology, 212, pp. 198-212.

Bastiaanssen, W.G.M., Pelgrum, H., Wang, J., Ma, Y., Moreno, J.F., Roerink, G.J. and Van der Wal, T., 1998b. A remote sensing surface energy balance algorithm for land (SEBAL).: Part 2: Validation. Journal of hydrology, 212, pp. 213-229.

Bausch, W.C. and Neale, C.M., 1987. Crop coefficients derived from reflected canopy radiation: a concept. Transactions of the ASAE, 30(3), pp. 703-0709.

Bausch, W.C., 1993. Soil background effects on reflectancebased crop coefficients for corn. Remote Sensing of Environment, 46(2), pp. 213-222.

Choudhury, B.J., Ahmed, N.U., Idso, S.B., Reginato, R.J., Daughtry, C.S.T., 1994. Relations between Evaporation Coeflqcients and Vegetation Indices Studied by Model Simulations. Remote Sensing of Environment, 50, pp. 1-17.

Cresswell, M.P., Morse, A.P., Thomson, M.C. and Connor, S.J., 1999. Estimating surface air temperatures, from Meteosat land surface temperatures, using an empirical solar zenith angle model. International Journal of Remote Sensing, 20(6), pp. 1125-1132.

Dugo, M.P.G., Escuin, S., Cano, F., Cifuentes, V., et al., 2013. Monitoring evapotranspiration of irrigated crops using crop coefficients derived from time series of satellite images. II. Application on basin scale. Agricultural Water Management, 125, pp. 92-104.

EarthExplorer, 2016.EarthExplorer Portal, USGS EROS. URL: http://earthexplorer.usgs.gov/ (12 Jan. 2016).

Er-Raki, S., Chehbouni, A., Guemouria, N., Duchemin, B., Ezzahar, J., Hadria, R., 2007. Combining FAO-56 model and ground-based remote sensing to estimate water consumptions of wheat crops in a semi-arid region. Agricultural Water Management, 87, pp. 41-54.
Forkel, M., Carvalhais, N., Verbesselt, J., Mahecha, M.D. Neigh, C.S. and Reichstein, M., 2013. Trend change detection in NDVI time series: Effects of inter-annual variability and methodology. Remote Sensing, 5(5), pp. 2113-2144.

Galleguillos M., Jacob F., Prevot L., Lagacherie P., Liang S., 2011. Mapping Daily Evapotranspiration Over a Mediterranean Vineyard Watershed. IEEE Geoscience and Remote Sensing Letters, 8(1), pp. 168-172.

Garcia-Tejero, I., Romero-Vicente, R., Jiménez-Bocanegra, J.A., Martínez-García, G., Durán-Zuazo, V.H. and MurielFernández, J.L., 2010. Response of citrus trees to deficit irrigation during different phenological periods in relation to yield, fruit quality, and water productivity. Agricultural Water Management, 97(5), pp. 689-699.

Glenn, E.P., Neale C.M.U., Hunsaker D.J., Nagler P.L., 2011. Vegetation index-based crop coefficients to estimate evapotranspiration by remote sensing in agricultural and natural ecosystems. Hydrological Processes, 25, pp. 40504062.

Holden, C.E., 2015. TSTools: Linking time and space visualization for remotely sensed time series. Zenodo. 10.5281/zenodo.34182.

Holden, C.E., 2015. Yet Another Time Series Model (YATSM). Zenodo. 10.5281/zenodo.17129.

Mateosa L., Gonzalez-Dugob, M.P., Testi, L., Villalobosa, F.J., 2013. Monitoring evapotranspiration of irrigated crops using crop coefficients derived from time series of satellite images. I. Method validation. Agricultural Water Management, 125, pp. 81-91.

Mu, Q., Heinsch, F.A., Zhao, M., Running S.W., 2007. Development of a global evapotranspiration algorithm based on MODIS and global meteorology data. Remote Sensing of Environment, 111, pp. 519-536.

Neale, C.M., Bausch, W.C. and Heermann, D.F., 1990. Development of reflectance-based crop coefficients for corn. Transactions of the ASAE, 32(6), pp. 1891-1900.

NRAA, 2011. Monitoring and Evaluation of Artificial Recharge of Ground Water Programmes/Schemes/Projects in the Rainfed Regions of Maharashtra. Study Report 3. National Rainfed Area Authority (NRAA), New Delhi, India, 2011, http://nraa.gov.in/pdf/gwp_maharastra_2011.pdf $\quad(26$ Feb. 2016).

O'Connell, M., Whitfield, D., Abuzar, M., Sheffield, K., McClymont, L. and McAllister, A., 2010. Satellite remote sensing of crop water use in perennial horticultural crops. Australian irrigation conference, Sydney, pp. 129-130.

Prihodko, L. and Goward, S.N., 1997. Estimation of air temperature from remotely sensed surface observations. Remote Sensing of Environment, 60(3), 335-346. 
QGIS Development Team, 2013. QGIS geographic information system. Open Source Geospatial Foundation Project. http://www.qgis.org/en/site/ (17 Nov. 2015).

Rafn, E.B., Contor, B., Ames, D.P., 2008. Evaluation of a Method for Estimating Irrigated Crop-Evapotranspiration Coefficients from Remotely Sensed Data in Idaho. Journal of Irrigation and Drainage Engineering, 134(6), pp. 722-729.

Shirgure, P.S., Srivastava, A.K. and Huchche, A.D., 2014. Water requirements in growth stages and effects of deficit irrigation on fruit productivity of drip irrigated Nagpur mandarin (Citrus reticulata). The Indian Journal of Agricultural Sciences, 84(3).

Tasumi, M., Allen, R.G. and Trezza, R., 2006. Calibrating satellite-based vegetation indices to estimate evapotranspiration and crop coefficients. In Proceedings of the 2006 USCID Water Management Conference, Ground water and surface water under stress: competition, interaction, solutions. pp. 103-112.

Verbesselt, J., Hyndman, R., Zeileis, A. and Culvenor, D., 2010. Phenological change detection while accounting for abrupt and gradual trends in satellite image time series. Remote Sensing of Environment, 114(12), pp. 2970-2980.

Verbesselt, J., Zeileis, A. and Herold, M., 2012. Near realtime disturbance detection using satellite image time series. Remote Sensing of Environment, 123, pp. 98-108. 